Wiegers, T., Graaf, H. de, Pal, K. van der. De opkomst van geboortecentra en hun rol in de zorgh TSG: Tijdschrift voor Gezondheidswetenschappen: 2012, 90(8), 475-478

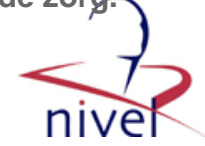

\begin{tabular}{|l|l|}
\hline $\begin{array}{l}\text { Postprint } \\
\text { Version }\end{array}$ & 1.0 \\
\hline Journal website & http://link.springer.com/article/10.1007\%2Fs12508-012-0162-1 \\
\hline Pubmed link & \\
\hline DOI & $10.1007 / s 12508-012-0162-1$ \\
\hline
\end{tabular}

This is a NIVEL certified Post Print, more info at http://www.nivel.eu

\title{
De opkomst van geboortecentra en hun rol in de zorg
}

TREes Wiegers ${ }^{*}$, HANNEKE DE GRAAF ${ }^{*}$, KARIN VAN DER PAL ${ }^{*}$

\section{ACHTERGROND}

Thuis bevallen is in Nederland altijd de gewoonste zaak van de wereld geweest. Pas sinds de jaren zestig van de vorige eeuw konden vrouwen met een ongecompliceerde zwangerschap kiezen voor een bevalling in een ziekenhuis zonder verwezen te zijn naar een gynaecoloog, voor een zogenaamde poliklinische bevalling, begeleid door hun eigen verloskundige. Een belangrijk Nederlands uitgangspunt, niet alleen in de verloskunde maar in de hele Nederlandse gezondheidszorg is de scheiding tussen eerstelijnszorg, die vrij toegankelijk is, en specialistische zorg (tweede en derde lijn) waar een verwijzing en dus een medische indicatie voor nodig is. In andere landen, waar die strikte scheiding ontbreekt, is bevallen in het ziekenhuis of in een geboortecentrum / geboortekliniek, meestal onder supervisie van een gynaecoloog, de norm.

Ook in Nederland zijn geboortecentra niet nieuw. Op verschillende momenten en om verschillende redenen werden geboortecentra opgericht en weer gesloten. De allereerste geboortecentra, toen kraamklinieken genoemd, werden gestart in 1883 ten behoeve van de opleiding van de vroedvrouwenscholen. ${ }^{1}$ Direct na de tweede wereldoorlog werden in verband met de woningnood en slechte behuizing ten behoeve van de verplaatste thuisbevalling door diverse organisaties en ziekenhuizen een groot aantal vrijstaande kraamklinieken opgericht in onder andere Den Haag, Amsterdam en Haarlem en diverse provincies. ${ }^{2-11}$ Later zijn de meeste hiervan weer gesloten. Rondom de eeuwwisseling werd in Nederland opnieuw gezocht naar mogelijkheden om vrouwen die, vanwege hun woonsituatie, niet thuis konden of wilden bevallen, een alternatief te bieden buiten het ziekenhuis. Om die reden ontstonden de eerste geboortecentra, ook wel kraam(zorg)hotels of geboortehotels genoemd, zoals in Rotterdam Noord (sinds 1997).

Toch begon de opmars van geboortecentra eigenlijk pas na de eeuwwisseling, toen er een schrijnend tekort was aan verloskundig zorgverleners, met name in de eerste lijn maar ook op de verloskamers in de ziekenhuizen. ${ }^{12,13}$ Verloskundigen konden door hun hoge werkdruk in sommige regio's geen thuisbevalling meer begeleiden en konden met hun cliënten ook niet zomaar in het ziekenhuis terecht. Als tussenoplossing werd gekozen voor een geboortecentrum, waar de verloskundige meerdere bevallingen tegelijk kon begeleiden zonder een beroep te hoeven doen op het ziekenhuis. Zo ontstonden er geboortecentra vlak naast of soms binnen de muren 
Wiegers, T., Graaf, H. de, Pal, K. van der. De opkomst van geboortecentra en hun rol in de zorgh TSG: Tijdschrift voor Gezondheidswetenschappen: 2012, 90(8), 475-478

van een ziekenhuis, zoals bij het Academisch ziekenhuis in Utrecht en het Martini ziekenhuis in Groningen, of los van een ziekenhuis zoals het Geboortehoes in Enschede. Dit was veelal een noodoplossing, omdat er voor bevallingen nu eenmaal geen wachtlijsten gehanteerd kunnen worden. Met het verdwijnen van de tekorten verdween ook een deel van die geboortecentra weer.

Maar de kijk op de verloskundige zorg was inmiddels wel aan het veranderen. Vooral vanuit de ziekenhuizen, maar ook door eerstelijns verloskundigen werd nu met belangstelling naar de nieuwe mogelijkheid gekeken: een geboortecentrum aanpalend aan of binnen de muren van een ziekenhuis of vlak bij het ziekenhuisterrein, zou de eerste en tweede lijn dichter bij elkaar brengen, de overdracht vergemakkelijken en tegelijk de druk op de verloskamers van het ziekenhuis verminderen, omdat er minder poliklinische bevallingen zouden komen. Deze (gedachten)ontwikkeling was al gaande toen Nederland opgeschrikt werd door de publicaties van EURO-PERISTAT ${ }^{14}$ waaruit een beeld naar voren kwam van hoge perinatale sterfte in vergelijking met andere Europese landen. De resultaten van deze studies werden vrijwel direct gekoppeld aan het Nederlandse verloskundige systeem, dat immers zo anders is dan in de ons omringende landen. De door de minister van VWS ingestelde 'Stuurgroep zwangerschap en geboorte' kwam in 2009 met een advies om de zorg anders in te richten en de samenwerking tussen eerste en tweede lijn te verbeteren. ${ }^{15}$ Daarmee verschoof ook de discussie rond geboortecentra van een alternatieve plaats van bevallen naar een alternatieve manier van werken: de mogelijkheid om de eerste en tweede lijn meer te integreren en de scherpe scheidslijn tussen beide echelons op te heffen, of wel: te 'ontschotten'.

\section{RECENTE ONTWIKKELINGEN}

De afgelopen jaren zijn er veel initiatieven ontstaan voor de oprichting van nieuwe geboortecentra. Momenteel zijn er zo’n dertig geboortecentra operationeel. Opvallend is de grote diversiteit die voortkomt uit de verschillende ontstaansgeschiedenis en organisatie van de geboortecentra. Dit uit zich bijvoorbeeld in de locatie van het geboortecentrum, variërend van niet aanpalend aan een ziekenhuis (bijvoorbeeld Geboortecentrum Amsterdam van Beatrijs Smulders) tot centra, die volledig in het ziekenhuis zijn geïntegreerd en ook wel "kraamsuites" worden genoemd. Ook onderscheiden de geboortecentra zich in de wijze van aansturing. Zo is een groot aantal geboortecentra opgericht door eerstelijns verloskundigen, al dan niet in samenwerking met de Stichting STBN en kraamzorgorganisaties, dan wel kraamzorgorganisaties alleen, dan wel een ziekenhuis alleen. Slechts in een enkel geval is een geboortecentrum opgericht door een samenwerkingsverband van de eerste en tweede lijn. Ook verschillen geboortecentra in de diensten die worden aangeboden zoals bijvoorbeeld pijnbestrijding tijdens de bevalling of de mogelijkheid om na de bevalling kortere of langere periode van de kraamtijd door te brengen in het geboortecentrum. Tot slot zijn er verschillen in visie tussen geboortecentra. Zo is Beval Centrum West in Amsterdam opgericht om vooral vrouwen te trekken die anders poliklinisch zouden bevallen, terwijl de geboortecentra in het Martini ziekenhuis in Groningen en het Academisch ziekenhuis in Utrecht vooral bedoeld waren om een alternatief te bieden voor thuisbevallingen. Ter illustratie is van twee initiatieven, het geboortecentrum Sophia in Rotterdam en het Beval Centrum West in Amsterdam, een korte beschrijving toegevoegd. 
Wiegers, T., Graaf, H. de, Pal, K. van der. De opkomst van geboortecentra en hun rol in de zorgh TSG: Tijdschrift voor Gezondheidswetenschappen: 2012, 90(8), 475-478

\section{FINANCIERING}

De vergoeding van bevallen in een geboortecentrum is altijd moeilijk geweest, ondanks het advies van de Centrale Raad voor de Volksgezondheid in 1977 aan het ministerie van Volksgezondheid dat als de vrouw kiest voor bevallen in het ziekenhuis, zonder medische reden, zij voor haar keuze geen financieel nadeel mag ondervinden. ${ }^{11}$ Ook de recente Stuurgroep Zwangerschap en Geboorte (2009) herhaalde dit advies. ${ }^{15}$ Tot op heden zijn deze adviezen niet opgevolgd door de overheid. ${ }^{16}$

De huidige geboortecentra zijn de eerste 3 jaren van hun bestaan financieel mogelijk gemaakt met behulp van de NZA innovatieregeling, eventueel aangevuld met extra financiering door een zorgverzekeraar of ziekenhuis. Binnen dit kader mochten de geboortecentra het tarief van een poliklinische bevalling bij de vrouw in rekening brengen ( $€ 494,25$ peildatum 2012), echter wanneer deze vrouw geen aanvullende verzekering heeft, moet zij de wettelijke eigen bijdrage van $€ 301,25$ zelf betalen. Dit innovatietarief is echter beperkt. Er wordt onder andere geen rekening gehouden met de hogere huisvestigingskosten en hogere kosten van 24-uurs vaste aanwezigheid van kraamverzorgenden en de bijbehorende specifieke bij- en nascholing van een geboortecentrum ten opzichte van een ziekenhuis. Ook kosten in verband met de wet op de toelating tot zorginstellingen zijn niet meegenomen. Ondanks al deze aspecten heeft de NZA op 1 januari 2012 middels een voorlopig besluit dit tarief voor de geboortecentra gehandhaafd. Momenteel zijn de bezwaarschriften van de diverse organisaties over dit tarief door de NZA in behandeling genomen. Deze problematiek geldt ook voor de financiering van de kraamdagen binnen een geboortecentrum. De huidige minister van VWS heeft aangegeven dat dit probleem tijdelijk zal zijn, omdat binnen enkele jaren de bekostiging van Geboortecentra onderdeel zal vormen van een integraal tarief Geboortezorg. Tot die tijd zoeken partijen naar een tussenoplossing. Als deze er niet komt, vormt dit een flinke bedreiging voor de opzet en/of continuering van geboortecentra.

\section{ONDERZOEK}

De afgelopen jaren is het aantal geboortecentra dus aanzienlijk toegenomen, maar de onderlinge verschillen zijn enorm. Een overkoepelende beleidsvisie over de plaats van geboortecentra in het verloskundige systeem ontbreekt en er is geen inzicht in de bijdrage die ze leveren aan de kwaliteit van de verloskundige zorg. Er is geen informatie over de effecten van een geboortecentrum op gezondheidsuitkomsten van moeder en kind of op ontwikkelingen als de toename in verwijzingen en interventies. Ook is er geen inzicht in de vraag of de zorg geleverd in geboortecentra aansluit bij de verwachtingen van vrouwen die er bevallen en hoe de zorgverleners het werken in een geboortecentrum waarderen. Tevens ontbreekt inzicht in de kosten van geboortecentra in verhouding tot de effecten van geboortecentra. In juni 2011 heeft ZonMw in het kader van het programma Zwangerschap en Geboorte een oproep gedaan tot het indienen van onderzoeksvoorstellen om inzicht te krijgen in de effecten van geboortecentra. In een unieke samenwerking tussen onderzoeksinstituten, medische centra, professionele organisaties en zorgverleners is een driejarig durend onderzoeksproject ontwikkeld, geleid door een 9-koppige projectgroep. Daarnaast is voor dit onderzoek een brede adviescommissie 
Wiegers, T., Graaf, H. de, Pal, K. van der. De opkomst van geboortecentra en hun rol in de zorgh TSG: Tijdschrift voor Gezondheidswetenschappen: 2012, 90(8), 475-478

samengesteld met vertegenwoordigers van STBN, KNOV, Midwifery Science, ZN, ActiZ, het Ouderschap, de verloskunde academies en individuele gynaecologen, verloskundigen, kinderartsen en kraamzorgaanbieders. Binnen het project wordt op brede en uitlopende wijze gekeken naar de effecten van geboortecentra. Kwalitatieve en kwantitatieve methoden zullen worden gebruikt en de resultaten zullen in samenhang worden geanalyseerd.

\section{NoOT}

Projectgroep Landelijke Evaluatie Geboortecentra: Dr Karin van der Pal-de Bruin (TNO), Dr Trees Wiegers(NIVEL), Dr Marc Bruijnzeels (Jan van Es Instituut), Dr Elske van den Akker-van Marle (LUMC), Drs Hanneke de Graaf (Geboortecentrum Sophia, Rotterdam), Prof.dr. Henk Akkermans (Universiteit van Tilburg), Dr Marlies Rijnders (TNO), Prof.Dr. Arie Franx (UMCU), Prof.Dr. Eric Steegers (ErasmusMc)

\section{CASUS: GEBOORTECENTRUM SOPHIA}

Na een voorbereidingstijd van zes jaar werd op 1 oktober 2009 het Geboortecentrum Sophia (GCS), gevestigd op het dak van het Sophia Kinderziekenhuis Erasmus MC, geopend. Het GCS heeft risicogeleide zorg als leidraad genomen voor de ontwikkeling van al haar interdisciplinaire (eerstelijns verloskundigen, kraamzorg, perinatologie, neonatologie en CJG) werkprotocollen, trainingen en expertisecentrum. Daarnaast heeft het in verband met haar cliëntenpopulatie nadrukkelijk aandacht voor de ketenfunctie tussen de disciplines binnen en buiten het GCS. Want hoewel de GCS cliëntengroep volgens de VIL (Verloskundige Indicatie Lijst) behoort tot de laagrisicogroep, blijkt uit evaluatieonderzoek dat deze cliëntengroep, vanwege hun sociaal economische omstandigheden en de sterke verhoging van allerlei risicofactoren, feitelijk tot een hoogrisicogroep behoort. Niet alleen vraagt dat meer begeleiding en instructie, ook levert dat een extra grote kans op een slechte verloskundige uitkomst (het fenomeen van 'risicocumulatie'). In verband met haar doelstellingen is door de stakeholders van het GCS bewust gekozen voor een gedeeld aandeelhouderschap. Dat houdt in dat het GCS een drietal aandeelhouders kent, te weten: de kraamzorg, het ziekenhuis en de vereniging van verloskundige maatschappen. Deze tripartite BV is binnen het landschap van de Nederlandse geboortecentra een unieke constructie, want meestal is een geboortecentrum óf namens de eerstelijns praktijken door de Stichting STBN óf door een kraamzorgorganisatie óf door een ziekenhuis alleen opgericht. Een wezenlijk voordeel is dat hiermee de verschillende in het geding zijnde belangen ook in zakelijke zin gelijkelijk vertegenwoordigd worden.

\section{CASUS: BeVAl CENTRUM West}

Beval Centrum West (BCW) is het eerste geboortecentrum dat geheel onder leiding staat van en beheerd wordt door verloskundigen zelf. Het BCW is een initiatief van 10 verloskundige praktijken uit Amsterdam west en is zelfstandig gehuisvest in het Lucas Andreas Ziekenhuis. Sinds 2007 kunnen vrouwen er bevallen. Het beheer is intussen tijdelijk overgenomen door de Stichting STBN om de organisatie bestuurlijk, financieel en logistiek beter neer te zetten.

Uitgangspunt van de verloskundigen is dat in het BCW vrouwen alles krijgen aangereikt om hun bevalling zo natuurlijk mogelijk, dus zonder onnodig medisch 
ingrijpen, te laten verlopen. De kamers zijn huiselijk ingericht met een tweepersoonsbed, baarkrukken, baarschelp, bal en een bevalbad. Een vaste groep kraamverzorgenden assisteert bij de bevalling.

Het inzicht dat de omgeving een belangrijke rol speelt in het verloop van de baring beperkt zich niet tot de inrichting en facilitering binnen het BCW. Tijdens de twee wekelijkse voorlichtingsavond in het ziekenhuis wordt door de verloskundigen ook de mogelijkheid om thuis te bevallen actief gepromoot.

In de visie van het BCW ligt de focus op het stimuleren van de fysiologische verloskunde, de veiligheid van de cliënt en de samenwerking tussen de verschillende disciplines. Zo worden kraamverzorgenden binnen het BCW geschoold in het assisteren tijdens de bevalling, inclusief de thuisbevalling, is er een VeiligIncidenten-Melding-procedure voor de eerste lijn bij overdrachtssituaties buiten en binnen het BCW, is er structureel overleg tussen alle disciplines van BCW en de afdeling verloskunde van het ziekenhuis en zijn er multidisciplinaire drills waarin de overdracht in een acute situatie wordt nagebootst met een lotuspatiënt.

\section{ARE BIRTH CENTRES THE RIGHT ANSWER TO THE CURRENT PROBLEMS IN MATERNITY CARE?}

Birth centres are a relatively new development in the Netherlands. Home birth is still very common but an increasing number of women prefer the 'safety' of a more clinical environment, especially since the publication of and all the media attention about the Euro-Peristat data on perinatal deaths. The Steering Group 'Pregnancy and Childbirth' recommended in 2009 more integration in the maternity care in the Netherlands, including the introduction of birth centres with close links to a hospital. Currently about 30 birth centres are operational, of various sizes and philosophies, located inside, alongside or detached from a hospital, with salaried personnel (midwives, maternity care assistants) or independent practitioners, with or without access to medical technology and methods of pain relief, and with various ways of funding. What is lacking is a general view on what a birth centre should be, how it should operate, and which population it should serve. What is also needed is insight into the effects of birth centre care on maternity care outcome variables, insight into clients' and care providers' experiences with birth centre care and insight into the costs of birth centre care compared to home birth or short-stay hospital birth. Therefore, in a unique cooperation between research institutes, medical facilities, professional organisations and care providers a research program has been developed to evaluate birth centres on aspects as integration of care, quality of care, experiences of clients and care providers, economic outcomes and implications for further implementation of birth centres in the Netherlands.

* Projectgroep Landelijke Evaluatie Geboortecentra

\section{LITERATUUR}

1. Geschiedenis van de Verloskunde Academie Amsterdam, Stichting Kweekschool voor Vroedvrouwen, sinds 1861. http://www.verloskunde-academie.nl/avag/Geschiedenis

2. Wiemann BJL. 'Opkomst en neergang van de ongehuwde moederzorg in Nederland (1880-1985)', Amsterdams Sociologisch Tijdschrift 1988: 337-371.

3. Brouwers, J. Van moederheil en Valkenhorst. Een geschiedschrijving Breda: 1995. 
Wiegers, T., Graaf, H. de, Pal, K. van der. De opkomst van geboortecentra en hun rol in de zorg. TSG: Tijdschrift voor Gezondheidswetenschappen: 2012, 90(8), 475-478

4. Stigter A de. Netjes in bed met een hoofddoek, Laatste Nederlandse kraamkliniek in Den Haag moet sluiten wegens geldgebrek. Reformatorisch Dagblad 8 december 1993, p17

5. Azivo nieuws Den Haag, 2008; 38: 4

6. Krol H, Pley G. Spaarne Ziekenhuis; van Diaconessenhuis en Mariastichting tot Spaarne Ziekenhuis. Haarlem, De Vrieseborch, 2005.

7. Haagse kraamkliniek mag toch verplaatst, na langdurige discussies. Reformatorisch Dagblad, 26 jul 1979, p4

8. Geldrop $\mathrm{G}$ van, Alten D van. De organisatievorm van een verloskundig centrum. Medisch Contact 1974; 29:466-470

9. Rapport werkgroep Geneeskundige Hoofdinspectie "Verloskundige zorg". 1968.

10. Kloosterman GJ, Seelen JC, Bruïne TLA de, Smalbraak HB, Eskes TKAB, Wering RF van. Rapport van de Commissie belast met de bestudering van de sociale verloskunde. Ned Tijdschr Verlosk Gynaecol 1968;68:435-6.

11. Alten D van, Kloosterman GJ. Kraamzorg. Ned Tijdschrift v Geneeskd $1981 ; 125: 2063-2067$

12. Graaf JP de, Stam-Happel M, Schuur O, Willems MC, Wieren WJ van, Steegers EAP. Bevallen in een geboortecentrum. Medisch Contact 2003; 58:1815-1817

13. Steegers EAP. Graaf JP de, Laudy JAM, Voorham T, Happel M, Denktas S, Spittje JD, Zee B van der, Huizer MC, Wildschut HIJ, Bonsel G. Recht op een goede start. Medisch Contact 2008; 63:100-101

14. EURO-PERISTAT Project, with SCPE, EUROCAT, EURONEOSTAT. European Perinatal Health Report. (2008) Available: www.europeristat.com

15. Stuurgroep zwangerschap en geboorte. Een goed begin. Veilige zorg rond zwangerschap en geboorte. Utrecht 2009

16. Regeling van de minister van Volksgezondheid, Welzijn en Sport van 12 juli 2012, nr. Z-3122968, houdende wijziging van de Regeling zorgverzekering in verband met maatregelen 2013 in het zorgpakket, Staatscourant Nr. 14946, 20 juli 2012 